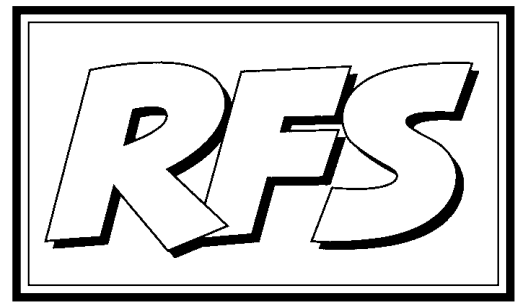

Revista de Fomento Social, 53 (1998), 271-284

\title{
Consecuencias políticas de la unión monetaria para la Unión Europea y para Europa ${ }^{(1)}$
}

En unos momentos en que abundan las expectativas y los interrogantes sobre la unión monetaria, que ya es un hecho para once países de la Unión Europea, RFS agradece vivamente a su autor la oportunidad de publicar este texto. Por la autoridad de quien lo escribe y por la claridad de sus planteamientos creemos ofrecer a nuestros lectores un testimonio de indiscutible interés. En él se subrayan las condiciones inexcusables para el éxito del euro, pero se expresan también algunas reflexiones de sumo interés sobre el futuro político de la Unión Europea. Aunque el texto está escrito antes de la Cumbre Europea de mayo, su contenido no ha perdido ni un ápice de su actualidad.

(*) Presidente del Bundesbank.

(1) Discurso pronunciado en el Congreso social «El euro y Europa: los efectos políticos de la unión monetaria», organizado por la Comisión de los Episcopados de la Comunidad Europea en Bruselas (20 febrero 1998). 


\section{I. [Lo que está en juego en la unión monetaria] (2)}

Ciertas contribuciones actuales al tema del euro me recuerdan aquellas palabras de San Mateo: «iCuidado con los falsos profetas!». Porque algunos ofrecen visiones apocalípticas, mientras que otros prometen el camino para el paraíso. Ambas posturas las considero falsas.

Ciertamente, el euro -futura moneda europea- no está exenta de riesgos. Pero equiparar automáticamente riesgos a catástrofes inevitables tiene poco que ver con un análisis realista. Y esta falta de realismo se advierte también en los que preconizan el euro como el remedio para todos los males económicos y políticos de Europa. El euro no puede ser ni será una tal panacea. Ninguna moneda podrájugar ese papel. Por el contrario, una moneda única plantea incluso nuevos desafíos.

Es cierto que el euro ofrece nuevas oportunidades en el terreno económico y en el político. Y los responsables tienen que procurar, con decisiones prudentes $\mathrm{y}$ adecuadas, que estas oportunidades se conviertan realmente en ventajas concretas.

Pero la unión monetaria no es ningún «Deus ex machina». Por sí misma, no resuelve los problemas de Europa. Su implantación no eliminará, sin más, el desempleo elevado, ni los problemas estructurales que existen a nivel de finanzas públicas o en el sistema social, ni la pobreza de los excluidos. Tampoco podrá paliar la falta de consenso político dentro de la misma Unión sobre cómo avanzar en el proceso de integración.

Naturalmente, la unión monetaria comporta también riesgos, en particular si su fundamento no muestra ser estable y duradero, o si algunos de sus participantes no quieren aceptar todas las consecuencias políticas y económicas de la moneda única, así como las reglas de juego que ella impone.

Por todo esto es tan importante que todos los países, ya antes de adherirse a la unión monetaria, sean plenamente conscientes de sus consecuencias profundas y las acepten de forma duradera. Porque la participación en la unión monetaria significa una vinculación económica y política nada desdeñable, y además para siempre.

(2) La conferencia está dividida en siete partes; pero los epígrafes colocados a cada una de ellas entre corchetes [ ] no pertenecen al texto original. 
En efecto, ser miembro de la unión monetaria no es lo mismo que participar en un acuerdo de cambios, como lo hacen ya numerosos países, por ejemplo en el marco del sistema monetario europeo. Los compromisos que derivan de la unión monetaria son muchos más estrictos y de un alcance muy superior:

1. La tasa de cambio fija pero ajustable, que se mantiene hasta ahora para el SME ha sido y sigue constituyendo todavía un compromiso limitado en el tiempo y que puede ser anulado en cualquier momento, aparte de que los márgenes establecidos hoy en torno a los tipos centrales son relativamente amplios. Adherirse a la unión monetaria significa, por el contrario, que la tasa de cambio queda fijada de forma definitiva, más aún, que queda suprimida. La unión monetaria es, por tanto, un camino sin retorno. No está previsto, ni jurídica ni políticamente, modificarla ulteriormente, ni siquiera salirse de ella. Ello ocasionaría elevados costes económicos y, sobre todo, perjuicios políticos cruciales.

2. La tasa de cambio no será lo único que quedará fijado. También la política monetaria en su conjunto quedará unificada y las decisiones serán tomadas a nivel centralizado para todos los países participantes. Habrá un sistema común de bancos centrales e instrumentos de política monetaria idénticos, cualesquiera que sean las tradiciones y las estructuras de cada país.

3. Por lo tanto la unión monetaria será como una comunidad de estados que unen sus destinos, en el terreno monetario, para lo mejor y para lo peor. Las consecuencias de los errores de política económica o monetaria cometidos por un país repercutirán rápidamente sobre los demás países a través de la moneda única, porque los mercados financieros y los ciudadanos considerarán a los países del euro como una única unidad monetaria.

Por todas estas razones se puede decir que la unión monetaria es algo completamente diferente de los sistemas de cambio existentes en la actualidad.

Por otra parte, la unión monetaria, a la que nos adheriremos en Europa al final de este año, es difícilmente comparable a los modelos que nos ofrece la historia. Es verdad que en la época del patrón-oro había también una cierta unificación monetaria. Pero el contexto es hoy totalmente diferente.

La participación del estado en el uso del producto nacional era en aquella época más bien inferior al 10 por ciento, mientras que hoy supera el 50 por ciento en la mayoría de los países europeos. Esto significa que en aquel tiempola política asumía una parte de responsabilidad mucho menos importante que ahora en el 
terreno económico y en el social. Además las economías podían entonces adaptarse mucho más fácilmente a las modificaciones de los mercados: porque el sector público, que representa ahora al menos la mitad de la economía nacional en casi todos los países de Europa, tiene mayores dificultades, como se sabe, para adaptarse que el sector privado.

En las circunstancias presentes, el camino a recorrer para llegar a la unión monetaria constituye un proceso excepcional en un doble sentido: por una parte, porque es apenas comparable con actuales o pasados sistemas de cambio; pero también en el sentido de que será el único intento de que dispondrá Europa durante bastante tiempo.

Por todo esto es necesario que este proyecto sea llevado a buen término. Pero, de una forma particular, debe constituir un éxito económico y político duradero para la integración de Europa.

\section{II. [Condiciones económicas y políticas para una unión monetaria]}

¿Cuáles son los factores que favorecen el éxito de una unión monetaria? ¿De qué tiene necesidad una zona monetaria?

En primer lugar, una zona monetaria que quiera ser estable y sin conflictos precisa de un fundamento económico sólido. En el terreno competitivo todos los países deben ser capaces de medirse de forma duradera con los otros estados participantes.

La llamada «teoría económica de la zona monetaria óptima» pretende determinar las condiciones gracias a las cuales las divergencias económicas son pequeñas, o, en el caso de que éstas surjan de forma temporal, la necesidad de ajuste de las tasas nominales de cambios se mantenga dentro de ciertos límites. Uno de los factores que juega aquí un papel especialmente importante es la movilidad del trabajo: en este sentido, no es nada probable que lleguemos a tener en Europa, ni siquiera a largo plazo, una movilidad de la mano de obra comparable a la de Estados Unidos.

En teoría, cuando existen diferencias de competitividad en el terreno económico, se puede naturalmente recurrir a otro medio para remediarlo: las transferencias de recursos públicos. En Alemania, pero también en otros países entre los que figura Italia, tales sistemas públicos de nivelación-como, por ejemplo, la redistribución del gasto público, los regímenes nacionales de seguros sociales o 
el reparto de los créditos en el presupuesto nacional-son utilizados para paliar las divergencias regionales.

Pero lo que es posible en el interior de un estado-nación y llega a ser aceptado a pesar de ciertos conflictos internos, es apenas realizable a nivel transnacional. Ya ahora algunos estados de la Unión Europea se sienten perjudicados por el peso que representan para ellos los sistemas comunitarios de financiación. Mientras no haya en la Unión Europea una mayor integración política, será difícil poner en marcha sistemas de transferencias a gran escala. E incluso si la integración política avanzara realmente, tampoco sería fácil la aceptación de los mismos.

En consecuencia, para que la unión monetaria que nacerá al comienzo del próximo año tenga un fundamento económico estable, será preciso que los países participantes tengan la fuerza y la capacidad de dominar ellos solos por símismos los cambios que se produzcan en los mercados, y que lo hagan sin recurrir a la modificación de las paridades y sin tener una política monetaria propia.

Junto a una base económica, la zona monetaria unificada tiene necesidad también de un fundamento político suficientemente explícito. Esto significa, entre otras cosas: un amplio consenso sobre el objetivo principal de la política monetaria; una perspectiva común sobre el significado de la estabilidad monetaria; una propensión y una capacidad duradera de mantener la necesaria disciplina en política financiera.

Estas exigencias económicas y políticas para que una zona monetaria sea perdurable explican por qué las precedentes uniones monetarias no pudieron sobrevivir si no llegaron a integrarse -más tarde o más temprano- en una unión política más amplia y duradera, y por qué hoy las fronteras monetarias coinciden en general con las de los estados nacionales.

La unión monetaria belgo-luxemburguesa constituye una excepción. Pero evidentemente no es igual que un país pequeño y muy flexible económicamente renuncie a su soberanía monetaria a que los haga todo un grupo de estados con países grandes como Francia o Alemania.

\section{III. [Unión monetaria y unión política: el Tratado de Maastricht]}

Una unión monetaria europea necesita, de forma irrenunciable y en alto grado, una base política y unos complementos. 
La cuestión de la relación fundamental a establecer entre unión monetaria y unión política ha sido ya frecuentemente objeto de debates apasionados, cosa que comprendo perfectamente. Dos cuestiones se plantean regularmente al respecto.

La primera es ésta: la unión política ¿es una condición previa para la unión monetaria o su consecuencia? ¿se dota ya desde ahora la unión monetaria a sí misma -y en este sentido la realidad se constituye en norma- del nivel de armonización económica y de integración política de que tiene necesidad? (tesis monetarista). ¿O la unión monetaria no puede ser sino el término de un proceso, a lo largo del cual se van claramente aproximando la economía y la política de los países? (tesis del coronamiento).

En el marco de esta discusión surge igualmente una segunda cuestión: ¿cuánta se piensa que debe ser esta integración política, y qué modalidad debe asumir? Tras esto puede entenderse una integración institucional creciente, es decir, el desarrollo y el reforzamiento de las instituciones comunitarias hasta dar nacimiento a una configuración de estados en forma de los Estados Unidos de Europa. Pero puede entenderse también una concepción más funcional de la integración: la integración política de países diferentes significaría entonces la formación de unos mismos valores, una mismas preferencias, unas estructuras económicas y sociales compatibles.

El Plan Werner de 1970 se había fijado como objetivo una integración política avanzada, garantizada por instituciones. Esta integración debería hacerse paralelamente al desarrollo de la unión monetaria. De este modo el Plan resolvía de una vez esa especie de nudo gordiano entre tesis monetarista y tesis del coronamiento.

La concepción de Maastricht es completamente distinta. No contempla -al menos en una primera etapa-la idea de una unión política con base institucional. Y la Unión Europea no ha formalizado - por lo menos hasta ahora- su intención original de modificar el Tratado de Maastricht con medidas que lleven a una institucionalización de la integración política.

Pero precisamente por esto la concepción de Maastricht impone ciertas condiciones de entrada, que son los criterios de convergencia. Estos deben garantizar un grupo de participantes relativamente homogéneos en cuanto a su estabilidad monetaria. Sólo los países que ya hayan alcanzado un alto nivel de estabilidad podrán llegar a ser miembros. Y deberán igualmente comprometerse 
a respetar una estricta disciplina presupuestaria, y de una forma duradera. Esto es al menos lo que exige el Tratado.

De este modo el Tratado de Maastricht se refiere claramente a un modelo funcional de integración.

Pero esta propuesta no es viable si no se toman verdaderamente en serio los criterios. Estos deben representar un test fiable que permita medir el grado de estabilidad alcanzado y si éste es duradero. Y las reglas en materia de disciplina deben ser absolutamente respetadas a largo plazo.

Ahora bien, por lo que respecta a la institucionalización de la integración política, la concepción de Maastricht supone una «construcción a dos niveles». Unifica la moneda, pero deja la mayor parte de las políticas económica, financiera y social como competencias nacionales. La Unión en cuanto tal sólo es responsable de una política común para el comercio exterior, la competencia y las ayudas; para la política económica y social de los Estados miembros únicamente puede dar orientaciones generales; y sólo dispone de un presupuesto más bien modesto (en torno al 1,2\% del PNB) con posibilidades de transferencias relativamente limitadas, cuyos efectos, por otra parte, parecen ser a veces muy poco transparentes. En manos de los Estados quedan los sistemas de compensación y de nivelación, en particular el grueso de los presupuestos públicos; ahora bien, deben atenerse a la regulación del artículo 104 c del Tratado de la Unión Europea, que impone una estricta disciplina en materia de gastos públicos y que ha sido concretado por el Pacto de Estabilidad y de Crecimiento; también continúan bajo la competencia de las instancias nacionales la legislación laboral, el derecho social y las disposiciones legales en materia de remuneraciones convencionales. Los Estados nacionales siguen siendo responsables, por tanto, de los factores esenciales de la política económica nacional.

Esta «construcción a dos niveles» presenta sus ventajas: se mantiene la competencia en el terreno de la política, y se mantiene también en gran medida la responsabilidad propia de las políticas nacionales.

Pero la «construcción a dos niveles» tiene también sus inconvenientes. Si algunos países participantes no practican una política adecuada, existe un alto riesgo de que el rendimiento diverja fuertemente de país a país dentro de la unión monetaria: y ya no será posible modificar los tipos de cambio independientemente o poner en acción políticas monetarias diferentes. En esas condiciones, la cuestión decisiva será: ¿cuánto tiempo tardará un país en estar dispuesto para 
corregir, y en corregir de hecho, los fallos en que haya caído por su propia política o por ajustes insuficientes, por ejemplo en el mercado de trabajo?

\section{IV. [Unión monetaria y unión política: más allá del Tratado de Maastricht]}

Al llegar aquí conviene quizás hacer la observación siguiente: el Tratado de Maastricht prevé ciertamente una «construcción a dos niveles», pero nada indica que haya que quedarse ahí. ¿No puede la unión monetaria dar un nuevo impulso a la integración política, incluso en el sentido de integración políticoinstitucional?

Por otra parte, la idea de facilitar el acercamiento político por la vía de la integración económica y monetaria ha estado siempre latente en la política europea y puede ser también considerada como una de las principales razones que están en el origen del proyecto de la unión monetaria. No hace mucho tiempo recordaba todavía Jacques Delors que la unión monetaria no era un fin en sí. Y en el Tratado de Maastricht se hace alusión igualmente al objetivo de una «unión cada vez más estrecha», aun cuando la fórmula no sea muy precisa.

Un impulso de este tipo podría imaginarse, en principio, de dos maneras.

Podría imaginarse en el caso de que la unión monetaria fuera un éxito. Tal éxito podría incitar a una integración más amplia y animar a encontrar soluciones europeas. Esta esperanza puede parecer hoy todavía demasiado incierta. Pero nosotros, los alemanes, estamos en buenas condiciones para saber que una buena moneda puede ayudar a forjar una identidad.

Pero podría imaginarse también desde una visión menos optimista. Incluso si no funcionara bien y fuera fuente de conflictos, la unión monetaria podría en teoría forzar a los Estados miembros a conceder mayores competencias comunitarias en otros dominios, y eso antes que los problemas hubieran llegado a ser demasiados. En tales condiciones, el reforzamiento de la integración política sería un recurso extremo más que un objetivo pretendido. En cuanto partidario convencido de la integración europea, yo no quisiera que la historia tomara este rumbo. Porque una situación así comporta grandes riesgos.

La unión monetaria es un corsé estrecho. Puede sostener. Pero puede también ahogar.

Si un país no pudiese mantener el ritmo económico de los otros o no quisiese 
seguir compartiendo el objetivo de estabilidad común, podrían surgir conflictos de inmediato.

Podrían surgir conflictos, por una parte, entre el Banco Central Europeo y la política de este país. Estos conflictos podrían amenazar la labor del Banco Central Europeo y reducir su capacidad de llevar adelante la política de estabilidad común, ya sea porque incitasen a los miembros del Consejo de Gobierno del Banco Central Europeo a un comportamiento ante todo «nacionalista», ya sea porque indujesen en la opinión pública posturas cada vez más divergentes en relación con el objetivo de una moneda estable.

Pero podrían, por otra parte, surgir conflictos entre las instancias políticas de los países participantes: por ejemplo, una lucha entre iniciativas políticas que pusiesen de manifiesto preferencias divergentes en las políticas económicas, o una batalla por nuevas transferencias de gran amplitud.

Sin duda que se dan conflictos ocasionales entre el banco central y los políticos o que surgen querellas sobre la distribución entre las regiones, incluso dentro de las zonas monetarias interiores a los estados nacionales actuales, y también en Alemania. Pero no hace falta mucha imaginación para comprender que tales conflictos tendrán un carácter muy distinto y alcanzarán una intensidad mayor si se mezclan con motivos y sentimientos nacionales, o si las partes implicadas no pueden apelar a una cultura común de estabilidad. Por esta razón la Unión Europea hará muy bien en limitar los riesgos desde el comienzo. Porque la unión monetaria no debe degenerar en una unión de conflictos.

Esto significa dos cosas. En primer lugar, significa que la opción de los países que participarán en la unión monetaria debe hacerse de acuerdo con los criterios de convergencia para que se llegue así a un conjunto bien homogéneo por lo que se refiere a la estabilidad: y la medida de esto sólo puede ser la capacidad comprobada y la voluntad política de orientarse de una forma duradera a una estabilidad común. En segundo lugar, significa que la opinión pública europea debe oponerse a que el curso de la política monetaria sea dictado por criterios nacionales: la política monetaria ha de ser decidida únicamente en función de la estabilidad duradera del euro, y no de cualesquiera otras preferencias nacionales. En particular es preciso dejar muy claro que las personas que estén al frente del futuro Banco Central Europeo no ocuparán ese puesto para representar los intereses de sus respectivos países: su única función consistirá en preservar la estabilidad de la moneda europea común. 


\section{V. [Estabilidad monetaria y expectativas político-sociales]}

Estoy convencido de que una unión monetaria consolidada con un euro duraderamente estable permitirá que la Unión Europea siga avanzando, tanto en el plano económico con en el político. Pero la estabilidad y el éxito no caerán del cielo.

Un euro estable presenta ventajas económicas considerables. Desaparecerán totalmente los riesgos de cambio y los costes de transacción entre los participantes. Los mercados financieros ganarán en profundidad y en amplitud, en beneficio de los inversores. Y sobre todo aumentará las transparencia de los mercados y se intensificará la competencia transnacional. De este modo un euro estable contribuirá al desarrollo del mercado común y acrecentará la imbricación económica de los países.

Ahora bien, no se debe perder de vista que se trata de ventajas macroeconómicas, de las que acabarán por beneficiarse todos los países implicados, en particular en el contexto de una globalización creciente, pero que no mejorará la pereza y el confort de las naciones participantes. La unión monetaria no es sinónimo de sosiego. Porque la intensificación de la competencia acarreará grandes cambios estructurales y exigirá un aumento de la flexibilidad, esfuerzo que deberán aceptar y llevar a cabo tanto las empresas, como los trabajadores, como la política económica y social de los Estados.

Esto hay que aceptarlo, si se quiere ser consecuente. Porque sería absurdo intensificar la integración económica y monetaria en la Unión Europea, y al mismo tiempo pretender someter nuevamente a control, a base de medidas reguladoras y protectoras, esta más fuerte competencia resultante.

Es cierto que muchos esperan bastante de la Unión Europea en el plano político-social. Piensan que ella puede remediar la incapacidad creciente de los Estados para asegurar la redistribución por medio de los impuestos, de las regulaciones y de los sistemas sociales. En su opinión, la Unión Europea debería, frente a la tendencia actual en favor de la integración, no intensificar la competencia, sino eliminar ese espíritu de competencia política entre los países europeos. E imaginan que el control político de los procesos económicos e sociales podría aumentar de forma decisiva.

Pero esta esperanza es ilusoria por varias razones. Ante todo, no se pueden atribuir a la competencia internacional los problemas que atraviesa hoy el estado 
de bienestar dentro de sus fronteras. Un sistema social que carece de incentivos, un sistema fiscal que estimula inversiones inadecuadas, una adaptación insuficiente a la evolución de la pirámide demográfica en la población activa, todo eso son procesos internos distorsionados. Y cuando no se toman a tiempo las medidas correctas sus efectos negativos se acumulan.

El estado de bienestar tal como se ha orientado en la Europa continental parece que choca cada vez más con sus propios límites, ya sea en el marco de la globalización o fuera de él. Ahora bien, la competencia internacional hace aparecer tales deficiencias mucho más pronto y de manera más universal, y además las castiga más severamente. Pero esta competencia no se limita a Europa. Está presente ya por todas partes y se generaliza cada vez más.

Y tampoco un super-estado europeo podría llevar adelante cualquier política económica o social. También él debería tomar en consideración la lógica que se le impone dentro de sus fronteras y la competencia global. Y las medidas políticas que no son buenas a escala nacional, tales como los programas de relanzamiento coyuntural a corto plazo que gravan las finanzas públicas y la estabilidad monetaria, no serán mejores por el mero hecho de que vengan de Bruselas.

A estas observaciones de carácter económico se añade también una consideración de naturaleza política. ¿Cómo podría la Unión Europea llegar a ser el sucesor legítimo del estado de bienestar tradicional sin suplantar casi completamente a los estados nacionales en lo político y en lo institucional? Un poder central con competencia para orientar los procesos sociales, redistribuir la renta y fijar los modos de regulación del mercado exigiría la puesta a punto de una instancia central con enorme capacidad de acción y de decisión, que además debería ser legitimada democráticamente de forma directa.

Pero la Unión Europea no parece querer evolucionar-al menos de momentoen esta dirección. Y está bien que así sea.

El mercado interior y el euro se inscriben en un contexto caracterizado por grandes exigencias económicas derivadas de sus desajustes internos y de la globalización, y, al mismo tiempo, en una Europa que, a largo plazo, no llegará a un nivel de integración política superior al de una unión de estados. Por todo ello los grandes proyectos de integración que existen actualmente-mercado interior y unión monetaria-no pueden dispensar a los Estados nacionales de su deber de hacer todo lo que está en sus manos para que sus economías vayan lo mejor posible. 
De hecho son numerosas las voces que se elevan para denunciar que, dada su falta de flexibilidad interna, algunos países no están suficientemente preparados para participar de la unión monetaria. Pero entre estos críticos hay algunos que esperan que la unión monetaria sea precisamente el factor que induzca a esos países a poner en práctica las reformas necesarias. Espero que tengan razón. Si no, los grandes países, como Alemania y Francia, tendrán mayores dificultades aún para afrontar eficazmente los problemas que les afectan, especialmente el desempleo elevado.

\section{VI. [Unión monetaria incompleta y Unión Europea heterogénea]}

La unión monetaria concentra hoy una gran parte de las esperanzas de llegar a una mayor y más intensa integración europea. ¡Ojalá se conviertan en realidad!

Pero hay otros que ven en la concepción de Maastricht más bien una fuente de discordia. Porque la unión monetaria acarrearía una división de la Comunidad, al menos en los comienzos. En 1999 habrá, con toda certeza, los «in» y los «out».

¿Se corre así el riesgo de que surjan divisiones en Europa, pero no entre la Unión Europea y los otros países, sino en el seno mismo de la Unión? El problema ha aparecido en relación con el Consejo del Euro-X, todavía de forma momentánea, pero con fuerza. Por el contrario, en el caso del Banco Central Europeo el problema había quedado regulado ya de forma institucional en el Tratado de Maastricht: además del Consejo de Gobierno del Banco Central Europeo, responsable de la política monetaria, existirá un Consejo General. Es pues el Tratado mismo el que hace esta diferenciación.

Pero puede incluso plantearse si la concepción de una unión monetaria parcial no constituye un cuerpo extraño a la integración. La respuesta también dependerá de en qué medida la integración europea debería buscar nuevos caminos para su ulterior desarrollo y para unir profundización y ampliación.

Al final de marzo tendrán ya lugar las primeras negociaciones con vistas a la entrada en la Unión. La ampliación, especialmente hacia los países de la Europa central y oriental, es, desde el punto de vista alemán, históricamente necesaria e inevitable, con la condición de que se fijen períodos transitorios adecuados. Porque estos países forman parte de Europa. Y porque la Unión no será creíble si no es percibida como una comunidad abierta: ¿no invita explícitamente el preámbulo del Tratado de Roma a los demás pueblos 
de Europa para que se asocien?

Pero la ampliación no hace a la Unión sólo más grande. Hace además más evidentes sus carencias institucionales: la cuestión de saber cómo la Unión puede ser (o llegar a ser) capaz de decidir y de actuar se plantea de forma cada vez más urgente. Y hace por fin a la Unión más heterogénea, en relación con su capacidad productiva, sus intereses y sus experiencias históricas.

¿Cómo puede la Unión Europea profundizar su integración política en estas condiciones? ¿Puede descartarse de entrada el peligro de que, si la integración en el seno de la Unión Europea no se hace de forma diferenciada, se llegue al estancamiento o a la regresión? ¿No podría ser el «modelo de círculos concéntricos pero no cerrados» un camino realista para avanzar hacia el futuro? Naturalmente el grado y la intensidad de los vínculos no deberían convertirse en una cuestión de prestigio nacional, sino que habrían de depender de las relaciones económicas y de la voluntad política estable de avanzar por la vía de la integración.

Así enfocado, la concepción de una unión monetaria, a la que al menos en principio no pertenecerán todos los Estados de la Unión, apenas debería obstaculizar la integración europea. Quizás esta situación permitiría descubrir otros dominios en los que seguir avanzando.

Por otra parte, una unión monetaria cuya estabilidad interna no fuera suficiente, no sólo constituiría un peligro para la cohesión en el terreno monetario de los países del euro, sino que podría incluso perjudicar el ulterior desarrollo de todo el proceso de integración.

También sería peligroso que la unión monetaria no se completara más adelante con compromisos políticos vinculantes, contentándose con hacer de ella un vasto sistema de transferencias. Esto podría amenazar, no sólo la aceptación de la unión monetaria, sino también su apertura al exterior: porque en una unión monetaria que fuera proveedora de transferencias a gran escala, los países beneficiarios de éstas se sentirían especialmente tentados de bloquear la entrada de nuevos y más débiles miembros.

Esta apertura, en virtud de la cual la unión monetaria no se convierte en un club cerrado, es sin duda la condición fundamental para poder mantener su acción integradora en el futuro. Pero el que esta acción de la unión monetaria conduzca a una integración paneuropea efectiva y progresiva dependerá también de que sea duraderamente estable y capaz de funcionar. Su estabilidad interna y la 
ausencia de conflictos es también importante para su apertura universal: porque un territorio dotado de una moneda estable en el tiempo y sin conflictos internos no tiene necesidad de protección hacia el exterior.

\section{VII. [Conclusión]}

Del éxito de la unión monetaria depende el destino de Europa. ¿Será el euro estable en el tiempo? ¿Formarán los países del euro una entidad suficientemente coherente en el terreno económico y político? Todo ello influirá decisivamente para una ulterior integración. Y para ésta será necesario un fundamento sólido y que pueda perdurar. Insistir en esta necesidad no es antieuropeo. ¡Al contrario!

El futuro de Europa no se decide en ceremonias. Se decide en el trabajo duro de cada día. Es importante que haya expectativas y esperanzas. Pero Europa precisa, al mismo tiempo, el realismo para detectar los peligros y reducirlos hasta donde sea posible. Yo sé bien que una unión monetaria sin riesgos no existe. Pero las decisiones de 1998 deben ser responsablemente tomadas, también frente a las generaciones venideras. Porque sus oportunidades económicas dependerán también del buen funcionamiento de la unión monetaria. 